\title{
The propensity to bargain while on a vacation
}

Tourism Economics 2017, Vol. 23(I) 150-167

(C) The Author(s) 2016

Reprints and permission: sagepub.co.uk/journalsPermissions.nav DOI: 10.5367/te.2015.0504 journals.sagepub.com/home/teu

@SAGE

\section{Metin Kozak}

Dokuz Eylul University, Turkey

\section{Antónia Correia}

CEFAGE, University of Algarve and Universidade Europeia, Portugal

\section{Giacomo Del Chiappa}

University of Sassari \& CRENoS, Italy; Senior Research Fellow, School of Tourism \& Hospitality, University of Johannesburg, South Africa

\begin{abstract}
This article assesses how tourists' bargaining motivations and attitudes moderate their willingness to return to Italy, where bargaining is perceived as one of the best ways to deal with sellers. A nonprobability quota sampling technique was used to survey domestic tourists in Italy through an online questionnaire which encompassed 26 bargaining values and one item to measure the likelihood that the tourists would bargain at the same destination in the future. The data comprised a total of 812 observations. An order probit model and marginal effects were estimated to measure the tourists' propensity to return to Italy for bargaining purposes. The study findings indicate that tourists' propensity to return for bargaining purposes is taken with the awareness that they will not obtain what they expected; as a matter of fact, they are unlikely to care about the final result but instead engage in this behaviour to have fun.
\end{abstract}

\section{Keywords}

bargaining, emotional value, shopping behaviour, social value, tourist behaviour, transaction value

\section{Introduction}

Shopping is one of the oldest and most common practices of human beings and in the case of holidays is even more prominent. Consumers mostly buy to satiate their needs, and societies are organized to make these needs endless. While on holiday, shopping goes beyond the postulate that consumers are rational and that they shop to maximize their utility. Even if this is verifiable in terms of shopping experiences, it is also true that materialism and social backgrounds put pleasure

\section{Corresponding author:}

Antónia Correia, CEFAGE, University of Algarve, Universidade Europeia, Campus de Gambelas, 8005-328 Faro, Portugal. Email: ahcorreia@gmail.com 
at the core of tourism shopping. Accordingly, Timothy (2005) argues that shopping in the tourism context is more a leisure experience than a utilitarian one. Even if tourists do not travel with the special intent to shop, they are likely to shop to interact with natives, and bargaining is therefore more likely to occur on holiday than in daily life. Shopping activity is recognized as a way of learning about the culture of destinations (Huang and Hsieh, 2011). This interaction is a form of trade that results in higher levels of satisfaction when tourists get discounts or, even without such discounts, when they are able to interact with local vendors (Darke and Dahl, 2003).

Bargaining has mostly been approached from an empirical economic perspective (e.g. Draganska et al., 2010; Fischer et al., 2007). Bargaining in tourism is addressed even more rarely (e.g. Tsang et al., 2011), despite the evidence that tourists from developed economies, where bargaining is not a commonplace practice, visit destinations such as China, Thailand, Turkey and India, where it is both commonplace and an expected feature of the tourist experience. From an economic perspective, shopping bargaining is a process in which two agents define a product's value through negotiation. The final attributed value is uncertain until the buyer and the seller reach an agreement (Brucks and Schurr, 1990). In game theory, bargaining is considered a challenge or a game to be won (Arnold and Reynolds, 2003) or a zero-sum two person game (Nash, 1950) driven by the willingness to maximize benefits, under the assumption that the agents involved in the trade are moved by greed and that neither is likely to accept a deal that will not lead them to a better position. Under the tenets of Pareto Optimal, this means that the ultimate result of a bargaining process is a win-to-win situation.

This definition of the bargaining game is grounded in economic theory and presupposes profit maximization. However, Kahneman and Tversky (1984) and Schindler (1998) demonstrate that a bargain also generates subjective value. In fact, even if consumers are not able to make any gains, they end up feeling satisfied by the process. Furthermore, Kahneman and Tversky (1984) prove that the discount amount is not as important as the level of involvement, time and energy spent. Darke and Dahl (2003) confirm that finding a bargain generates more satisfaction than the amount of money saved. Therefore, bargain shopping should be discussed as an activity with hedonic value (both utilitarian and non-utilitarian). The shopping literature includes limited empirical research on bargaining from a hedonic perspective (Cox et al., 2005). Consumers with an orientation for bargaining are characterized as economic shoppers, rational and very efficient at playing the bargaining game, as they have complete information and a clearly stated price reference (Stone, 1954, Bellenger and Korgaonkar, 1980). However, this is not the case in tourism contexts. In tourism shopping, interaction between tourists and sellers is mandatory, but tourists do not really search for products that will satiate their needs; instead, they buy mementos and artefacts, and the price reference for these products is unknown. This follows Bettman (1979) who states that information uncertainty is what distinguishes bargaining from post-price shopping. In bargaining, the final value is uncertain until the buyer and the seller reach an agreement.

This uncertainty challenges consumers' bargaining skills and may lead to a feeling of pride and achievement that the system has been beaten (Schindler, 1989). Under these assumptions, it may be assumed that bargaining has a hedonic value that is grounded in transaction utility theory (TUT; Thaler, 1985) and equity theory (Bagozzi, 1975). TUT states that consumers derive utility through the material and psychological consequences of the exchange. TUT relies on acquisition value and on the perceived merit of the deal itself. The psychological source of bargain value arises from perceptions of the fairness of the offer (Darke and Dahl, 2003). Complementarily, equity theory provides a framework for understanding how social cues moderate perceptions of fairness (Bagozzi, 1975). In particular, the equity principle states that exchanges tend to be perceived as fair when the ratio of cost and benefit is the same for all the participants. 
On the basis of these tenets, the present study aims to assess how utilitarian and non-utilitarian bargaining values in tourism contexts moderate the intentions of tourists to return to the same destination to bargain. The analysis accounts for the subjective experiences of consumers when being offered a discount, and we believe that this approach is able to unveil the non-utilitarian sources of the value involved. An order probit model is used to test both the influence of utilitarian and non-utilitarian values of shopping bargaining while on holiday and the intentions of tourists to return to engage in bargaining shopping experiences. In general terms, this article measures the importance of bargaining in retaining tourists to revive shopping places. Data were gathered based on a self-administered questionnaire survey, applied to 812 tourists visiting Italy who engaged in shopping during their stay.

This study fills a void in the literature, for despite the volume of existing research into shopping behaviour (e.g. Chang et al., 2006; Kim et al., 2011; Lehto et al., 2004; Lo and Qu, 2015; Turner and Reisinger, 2001), it remains unclear what shopping satisfaction and pleasure mean to consumers (Falk and Campbell, 1997). This is especially evident in bargaining, which for some consumers may be considered either a chore or a source of pleasure (McKercher and Lui, 2014; Schindler, 1989). The pleasures of bargaining have rarely been addressed in the literature (Charny, 1991; Kozak, 2015; McKercher and Lui, 2014), despite the evidence that such behaviour enhances tourists' shopping experiences (Falk and Campbell, 1997), which is one of the most important determinants of tourist satisfaction (Cox et al., 2005; Pizam and Sussmann, 1995). More recently, Tsang et al. (2011) have concluded that bargaining contributes positively to tourists' well-being.

In addition to filling a gap in the literature, the contributions of this article to the existing body of knowledge are threefold. From theoretical and methodological points of view, the article provides a framework for testing bargaining behaviour as a moderator, influencing the destination choice of tourists as well as their motivations to bargain. The model also stresses the importance of separating utility transaction values from non-utilitarian values as determinants of bargaining seeking behaviour. Finally, the results of the study are expected to provide tourism managers with a better understanding of the factors contributing to enhanced shopping experiences at tourism destinations. Furthermore, this study revives a topic that is of the utmost importance for tourism destinations and on which research has substantially decreased, probably due to the proliferation of malls, where interactions with sellers happen only at the cash desk. As such, this study calls the attention of policymakers to the importance of bargaining in order to revive traditional shopping streets in tourism destinations.

\section{Literature review}

Shopping has long been recognized as a primary motive in tourism experiences (e.g. Law and Au, 2000; Lehto et al., 2004; Wang, 2004; Wong and Law, 2003). Bargaining experiences allow tourists to taste the authenticity of their chosen destination. For instance, like in some other Mediterranean destinations, Italian open-air markets are one of the most recognized bargaining paradises worldwide. Bargaining is recognized as a zero sum game with benefits for buyers and sellers, in which both parties are aware of the rules. This is not the case for tourists visiting unfamiliar places. Nevertheless, such tourists persist in engaging in bargaining games while on vacation in order to experience negotiation trials in open-air markets and to interact with local people.

Murphy et al. (2011) argue that bargaining pleases shopping tourists. In the same vein, Chang et al. (2006) demonstrate the psychological effects and social ties of bargaining that drive the shopping experiences of tourists. Accordingly, Yuksel (2007) proves that bargain opportunities, 
interaction with shoppers and vendors and browsing and socializing all increase shopping entertaining opportunities. Cox et al. (2005) argue that freedom to browse and to argue with vendors without time or budget constraints is only possible while on vacation. The theoretically explanation for this is provided by TUT and equity theory under the tenets of game theory.

\section{TUT and equity theory}

Bargaining is an exchange game, in which players look for price fairness and fair social exchange. This can be discussed in terms of TUT (Thaler 1985) and equity theory (Adams, 1965). TUT introduces the price perception of fairness, while equity theory introduces the satisfaction derived from the existence of fairness in social exchanges.

TU assesses price fairness by comparison with the reference price that consumers possess. Under this assumption, TU increases if the price offered meets or exceeds the expectations of consumers (reference price). At this point, the price obtained through bargaining is considered fair. TUT frames the price but also assumes that consumers perceive the fairness of the price based on different judgments, for instance, perceptions of the quality/cost ratio (Kahneman et al., 1986), previous bargain experiences or differences between the initial and the final price (discount ratio). Overall, the discount amount increases the perception of fairness of the price and decreases the price search. This means that consumers tend to perceive the price as fair when the discount increases, and this is explained by the increase in TU. As such, the value of bargaining is explained by the perceptual dissonance between the reference price and the transaction price. The question that remains to answer is whether TU or acquisition utility is responsible for these effects.

Perceived transaction value is defined as the psychological satisfaction consumers obtain from the financial profit they may gain from the deal (Grewal et al., 1998). The acquisition value refers to the perceived net gains associated with the purchased product (Grewal et al., 1998). The acquisition value is the ratio of utility versus the price paid for the product (Grewal et al., 1998; Thaler, 1985). More concretely, this means that acquisition value refers to gains or losses derived from the purchase transaction (Thaler, 1985). Other authors have proved that the acquisition value referred to the reservation price is limited to capturing the total value of the acquisition gathering (Grewal et al., 1998, Sheth et al., 1991; Sweeney and Soutar, 2001). Quality, price, social values and emotional values should all be considered part of the acquisition value.

On the other hand, the transaction value is assumed to be the psychological satisfaction obtained from the perception of taking advantage of the deal (Grewal et al., 1998). In other words, the transaction value is the pleasure involved in finding a good deal rather than from the product acquired (Lichtenstein et al., 1990; Thaler, 1985). This explanation lends itself to equity theory, which supports the reasoning of the social cues related to bargaining, namely luck in finding the best deal without effort (the hypothesis of the lucky shopper; Stigler, 1987) and the ego expression of pride in possessing bargaining skills (the hypothesis of the smart shopper; Schindler, 1998). Overall, it may be assumed that obtaining a good discount and finding the best bargain will elicit a greater transaction value.

Accordingly, consumer attitudes seem to be driven by psychological processes rather than mere financial goals (Darke and Dahl, 2003). Kahneman and Tversky (1984) illustrate this assumption, proving that even when the amount saved is the same, the discount percentage leads consumers to engage in differing degrees of effort. This happens because cognitions distort the true value of the deal. The empowerment of being able to bargain is a consumer driver that has nothing to do with the economic benefits that may be gained. This is consistent with TUT (Thaler, 1985). 
Bargaining can be explained as involving a combination of luck and bargaining skill. Whereas luck justifies the satisfaction involved in surprise, satisfaction derived from skill relies on price and accomplishment (Darke and Freedman, 1995). This justifies different explanations of fair price, where fair price may be related to the best price (smart shopper), the lowest price (lucky shopper) or the expected price (TU). As such, perceptions of fairness are central to TU but are also connected to social exchange (smart shopper or lucky shopper), and this relates to equity theory (Adams, 1965; Bagozzi, 1975). In sum, TUT postulates that consumers judge the fairness of prices by price references, whereas equity theory frames the discussion of fairness in terms of social cues, such as the price other customers were able to negotiate, as well as the relationship consumers establish with sellers. Empirically speaking, there may be great variations in price, and each seller may make discounts available to some consumers and not to others. These strategies may be economically explained in terms of game theory (Nash, 1950).

\section{Bargaining: A game with economic and psychological benefits}

According to Nash (1950), a game involves two persons: the seller and the buyer. The former proposes a price for the transaction, and if the buyer accepts, the transaction is over with shared benefits for both. The game is also over if buyer and seller fail to reach an agreement, but this time with no gain for either. Greedy attitudes, however, lead the seller to demand the highest price, whereas the buyer expects to spend less on buying the product. This lack of agreement is what nurtures a non-zero-sum game. It is a game in which buyers and sellers do not have similar opportunities to deal. This is even more evident in environments where buyers are aware that sellers will accept any offer. As such, it may be assumed that bargaining behaviour is learned rather than innate. Learned bargaining behaviour in economics is assessed as game theory, whereas in psychology, the game is assumed to be a social interaction.

The bargaining game is assumed to be a game, where the buyer and the seller are highly rational, have complete information and equal skills to bargain, and where each has full knowledge of the tastes and preferences of the other - the tenets of a zero-sum game. In one way or other, the game happens if the rational expectations of both players can possibly be met by agreement. Hence, there should be an available anticipation that gives each the amount of satisfaction he or she should expect.

Shopping bargaining games are established on the assumption that buyers and sellers both seek to establish and maintain a beneficial trading relationship (Dalrymple et al., 2004). Each interacts with the other in order to understand the other's expectations and negotiation skills (Varey, 2001). If agreement is set, both parties expect to achieve the best bargain they can while meeting their responsibilities.

Furthermore, it is assumed that with a small number of buyers, the opportunities of the seller are limited. Inversely, when one customer accounts for a large share of supplier sales, it is the buyer who absorbs the negotiating power. Furthermore, the greater the bargaining power of buyers, the less advantage this is for sellers. Therefore, once buyers know that they can influence sale conditions and terms, including the price, they may be willing to engage in more assertive bargaining behaviour than when they know they lack such an influence. After all, not all buyers have equal bargaining power with sellers. In fact, some buyers may be less sensitive than others to price levels (Proctor, 2000), and others may lack the skills needed to negotiate a better price, decreasing their propensity to bargain. 
Furthermore, understanding the cultural restrictions and motives that have driven the customer's purchase decision will allow marketers to know, for example, what target price should be aimed for (Souiden, 2002), depending on the type of customer. Hence, cultural values and prospect values will influence the decision of both buyers and sellers to engage in bargaining, which places this game on two borderlines - psychology and economics. When both are positive, the propensity to bargain will increase.

\section{Research design and hypotheses}

This article examines how utilitarian and non-utilitarian factors and social cues enact tourists' propensity to bargain at a level that may determine their return intentions. The bargaining seeking model proposed assesses a tourist's willingness to return to Italy with the purpose of bargaining based on TUT and equity theory. An exploratory factor analysis (EFA) allows us to depict the main factors that explain the transaction as well as social and emotional values and gender effect. The data used are of an ordinal type, and as such an order probit model is a good way of testing the propensity to return to bargain at the same destination (Ben-Akiva et al., 1997). The choice of each component was based on the literature review. The contribution of this article depends upon the identification of the relationship between the transaction value, emotional value and social value that tourists obtain from their bargaining experience in Italy that will make them likely to repeat the experience during future visits. Furthermore, the role of socio-demographics in return intentions, gender effects and overall satisfaction with the experience is also measured. The list of hypotheses tested in this study is as follows:

Perceived transaction value is the psychological satisfaction tourists obtain when they take advantage of a price deal (Grewal et al., 1998). The advantage of the price deal is related not only to the discount but also to the quality of the deal per se. Assuming that this is a game, and the award is the product, and in accordance with Schindler (1989), the transaction value should be assessed as an object to win, the winner being the smart or the lucky shopper. Tauber (1972) argues that the pleasure of bargaining relies on the competition between buyers and sellers. For instance, buyers feel satisfied when they are able to obtain a lower price than other buyers. A winning position would elicit a sense of achievement and excitement in their negotiating skills (Darke and Dahl, 2003; Schindler, 1989). Furthermore, reaching a good deal contributes to a sense of pride, smartness and competence (Holbrook et al., 1984). Cox et al. (2005) prove that the pleasure of bargaining is higher than the pleasure derived from browsing, pampered or mingling.

H1: Transaction values positively influence return intentions with the purpose of bargaining.

Shopping acts are always embedded in emotional states. Holbrook and Hirschman (1982) depict the emotional aspects of consumption process as hedonic, symbolic and aesthetic. This means that aside from the utilitarian aspect of consumption, this experience is also embedded in enjoyment and pleasure.

H2: Emotional values positively influence return intentions with the purpose of bargaining.

On the other hand, social values refer to acceptance and conformity with consumers' social groups. In product choice, consumers are influenced by the observation of the behaviour of their reference groups or even by direct interaction with the group to be accepted into (Bearden and Etzel, 1982; Moschis, 1976). Social value in product consumption usually refers to the influence of 
the value-expressive reference group to fulfil the desire to be accepted or to be in conformity with others (Bearden and Etzel, 1982; Park and Lessig's, 1977). Bearden and Etzel (1982) argue that the opportunity for observation and the visible signs of purchasing behaviour are critical in influencing purchase decisions.

H3: Social values positively influence return intentions with the purpose of bargaining.

Looking at the cross-gender differences from different research fields, we find, for instance, that both male and female employees are more likely to have female managers or supervisors on the committee as recruiters. This is because employees perceive that female recruiters are more likely to offer them a job and a salary on a higher scale than their male counterparts (Pinar et al., 2011). As regards the issue of gender in consumer behaviour, Tanguma et al. (2009) report that female customers obtain lower prices than their male counterparts. However, the common belief is that significant differences exist based on gender in bargaining and negotiation behaviour, with women being apparently slightly more collaborative than males (Kim and Kim, 2005). This has been considered a misconception by some researchers who suggest that gender differences in negotiation behaviour are not absolute (Kennedy, 2008; Yurtsever et al., 2013). Yurtsever et al. (2013), for example, argue that this could be due to the mediating effect that cognitive reappraisal and cognitive reappraisal suppression exert on the relationships between gender and negotiation achievements. Cognitive appraisal can be defined as "a form of cognitive exchange that alters the way one thinks about and perceives a situation, and can elicit emotion in a way that changes the emotional effects produced by a situation" (Yurtsever et al., 2013: 570).

Gender differences in consumer bargaining behaviour could be due to the existence of internal traits (males and females are inherently different) or external situations (they are treated differently by society, and they respond differently to social environment stimuli). Furthermore, quite interestingly, results of prior gender-oriented research confirm that females who are more socially strategically oriented when bargaining are able to fare better when they negotiate and bargain on behalf of another person, namely the so-called other advocacy (Amanatullah and Morris, 2010). Furthermore, when the social cost of negotiating is eliminated in the condition of other advocacy, females and males express the same assertive behaviour in bargaining and obtain the same outcomes; this suggests that culture and related social norms can mediate the gender differences in bargaining behaviour (Amanatullah and Morris, 2010).

H4: Gender differences in the bargaining game exchange positively influence return intentions with the purpose of bargaining.

The cognition-affect-intention paradigm of Bagozzi (1982) and Fishbein and Ajzen (1975) suggests that cognitions trigger affective responses, and affective responses are the antecedents of behavioural intentions. In this line, Hunt (1993) proves that satisfaction is primarily an affective evaluative response. Shopping enjoyment is characterized as an individual's personality trait, resulting in their deriving greater pleasure and enjoyment from shopping trips than other consumers (Bellenger and Korgaonkar, 1980). The intensity of bargaining and bargaining to maintain psychological well-being are also found to positively influence overall shopping satisfaction as well as the intention/likelihood to return and to recommend (Tsang et al., 2011). Furthermore, previous experience also plays an important role in future intentions (Kozak, 2001). 
H5: Satisfaction in the bargaining game exchange positively influences return intentions with the purpose of bargaining.

H6: Previous bargain experiences positively influence return intentions with the purpose of bargaining.

\section{Methodology}

The target population for this study was defined as a group of Italian tourists travelling to Sardinia, Italy. Data were collected through interviews conducted by a group of five previously trained interviewers who were directly supervised by one of the authors. Interviewers were instructed to deliver the questionnaire in the area of Gallura-Costa Smeralda, one of the most famous and frequented destinations located in the north-east of the island of Sardinia. Respondents were interviewed in different accommodation settings (hotels, agritourism sites, etc.) and in different locations (international airport, port, bars, beaches, etc.), so that it was possible to capture different guest profiles and different perceptions, motives and experiences as regards travelling to Sardinia. To avoid some bias related to the topic (bargaining), the questionnaires were selfadministrated. The criterion for selecting participants was that they had participated in shopping activities during their stay in Sardinia. Data collection was performed during the summer of August 2012, and of 1030 questionnaires collected, 812 were selected for further analysis, representing an acceptable response rate of $79 \%$ (Dillman, 1978). The remainder were discarded, mostly due to the respondents' lack of participation in shopping experiences during their visit. Missing data were also discarded. The reason for being so strict in data selection relates to the aim of the article, which is to assess the propensity of tourists to return to the destination with the purpose of bargaining.

A survey consisting of three parts was developed in order to test the proposed hypotheses. The first hypothesis comprises a set of statements derived from the literature to measure bargaining propensity, depicting TU value, emotional and social value and gender differences. The second presents the likelihood of returning to Sardinia to bargain. The third part considers the socio-demographic characteristics of the respondents. The set of variables included in each of the four constructs, as well as the authors who contributed to their identification, are illustrated in Table 2. Since some of these statements might have been regarded by respondents as in some way difficult to understand, the statements were rewritten in a more understandable way. The survey was prepared in Italian, since the focus of the analysis is on Italy and Italian tourists. A five-point scale of concordance was used, ranging from $1=$ totally disagree to $5=$ totally agree.

As reported in Table 1, the larger proportion of respondents had a positive attitude to engaging in bargaining (67.5\%). This attitude is more evident in tourism contexts $(71.8 \%)$. Overall, most had a high level of education (61.4\%) with a good standard of life (47.9\% had an annual income in excess of $€ 10,000)$. The respondents are young, many in the category of $25-34$ years old $(49.9 \%)$. In respect to their attitudes towards bargaining, most do not decide their visit destination based on the possibility of bargaining $(55.3 \%)$, but they are likely to recommend bargaining to others (49.4\%). Even though bargaining does not drive their destination choice, they bargain while shopping when they are at the destination $(70.7 \%)$.

Table 2 outlines the variables comprising each construct derived from the existing research of several authors in accordance with the EFA. A reliable measure of the constructs was demonstrated 
Table I. Sample characterization.

\begin{tabular}{|c|c|c|c|}
\hline Socio-demographic & $\%$ & Bargaining attitudes & $\%$ \\
\hline Gender & & Frequency of bargaining & \\
\hline Female & 31.7 & Never & 32.5 \\
\hline Male & 68.3 & Sometimes & 45.0 \\
\hline Age groups & & Always & 22.5 \\
\hline From 18 to 24 years & 12.8 & Frequency of bargaining in a tourism context & \\
\hline From 25 to 34 years & 49.9 & Never & 28.2 \\
\hline From 35 to 44 years & 21.7 & Sometimes & 41.3 \\
\hline+45 Years & 15.6 & Always & 30.5 \\
\hline School level & & Destination choice based on bargaining opportunities & \\
\hline Secondary & 31.6 & No & 55.3 \\
\hline University & 61.4 & Recommend bargaining to others & \\
\hline Average annual income & & Yes & 49.4 \\
\hline Less than $€ 10,000$ (net) & 32.4 & Bargain experiences on the current holiday & \\
\hline More than $€ 10,000$ (net) & 47.9 & Yes & 70.7 \\
\hline Prefer not to answer & 19.7 & & \\
\hline
\end{tabular}

by a factor analysis using maximum likelihood extraction with varimax rotation. The reduction of the initial 26 variables into four new factors accounted for $52.2 \%$ of the total variance (KaiserMeyer-Olkin $(\mathrm{KMO})=0.93$; Bartlett test: $p=0.00)$. In this analysis, all the items which show low reliability were dropped from the analysis, such as "I bargain because there is no price label," "Travelling in a group encourages me to bargain," and "Bargaining helps me to express myself."

Considering the meaning of bargaining values, grouped with higher loadings and the literature, the bargaining factors are transactional utility, emotional, social value and gender differences. As presented in Table 2, the internal consistency of these factors was measured by the corresponding Cronbach's $\alpha$ coefficients that are good (superior to 0.7 in all cases).

Based on mean scores, the EFA suggests that the most relevant indicators in the dimension "transactional value" are controlling the budget (3.20) and low expectations about the products (3.22), suggesting that tourists are rational and reach their decisions based on their budget constraints (Grewal et al., 1998). This is not surprising considering the sample, half of which is comprised of young adults. This result is reinforced by the importance of discounts (3.13) and value for money (3.09) in ensuring a better situation (Pareto Optimal). The most important factor is the opportunity to bring down the price, which usually starts very high (I bargain because sellers start by saying a high price, 3.30). This suggests that tourists enjoy demonstrating their negotiation skills (Darke and Dahl, 2003; Schindler, 1989).

Emotional values are explained by the entertainment the tourists derive from the experience (bargaining makes me have fun, 2.90), excitement (bargaining makes me excited, 2.76), indifference to a winner position (I bargain but I'm not really interested in the final result, 2.33) or the happiness the game brings (Bargaining makes me happy, 2.33). The composition of this construct shows clearly that shopping is a leisure activity, where interaction is more than welcome (Holbrook and Hirschman, 1982). Furthermore, these findings also suggest that the result of the game is not a concern, but self-confidence and interaction are, as in Kahneman and Tversky's (1984) and Schindler's (1998) studies. This suggests that the winning position in a bargain game is the interaction and the enjoyment of the bargaining experience itself. 
Table 2. Exploratory factor analysis.

\begin{tabular}{|c|c|c|c|c|}
\hline & Eigenvalue & $\begin{array}{l}\text { Cronbach's } \\
\alpha / \text { means }\end{array}$ & $\begin{array}{l}\text { \% Variance } \\
\text { explained/ } \\
\text { standard } \\
\text { deviation }\end{array}$ & Authors \\
\hline Transactional utility value & & 0.870 & 17.2 & Westbrook \\
\hline I bargain because sellers start by saying a high price & 0.529 & 3.30 & 1.214 & and Black \\
\hline I bargain due to my budget constraints & 0.567 & 2.97 & 1.240 & $(1985)$ \\
\hline I bargain to buy more & 0.587 & 2.73 & 1.316 & \\
\hline Bargained-for products usually meet my expectations & 0.678 & 3.22 & 1.116 & \\
\hline Bargaining makes me control my budget & 0.684 & 3.20 & 1.199 & \\
\hline Bargaining is value for money & 0.640 & 3.09 & 1.199 & \\
\hline $\begin{array}{l}\text { Bargaining makes me develop my communication with } \\
\text { the seller }\end{array}$ & 0.540 & 2.61 & 1.282 & \\
\hline I get discounts through bargaining & 0.565 & 3.13 & 1.089 & \\
\hline The bargain products have an acceptable quality & 0.608 & 3.05 & 1.089 & \\
\hline Emotional value & & 0.832 & 12.4 & Sweeney \\
\hline Bargaining makes me excited & 0.672 & 2.76 & 1.263 & and \\
\hline Bargaining makes me happy & 0.577 & 2.33 & 1.140 & Soutar \\
\hline Bargaining makes me have fun & 0.783 & 2.90 & 1.293 & $(200 I)$ \\
\hline I bargain but l'm not really interested in the final result & 0.512 & 2.33 & 1.279 & \\
\hline Social value & & 0.795 & 12.010 & \\
\hline I follow the recommendations of my peers to bargain & 0.596 & 2.90 & 1.130 & \\
\hline I bargain because this is what my friends also do & 0.529 & 2.85 & 1.105 & \\
\hline Bargaining on holidays is easier for me & 0.509 & 2.95 & 1.254 & \\
\hline Bargaining helps to communicate my self-identity & 0.616 & 2.08 & I. 147 & \\
\hline Bargaining is a sort of entertainment & 0.584 & 2.70 & 1.051 & \\
\hline Bargaining is a kind of culture & 0.587 & 3.07 & 1.148 & \\
\hline Gender differences & & 0.869 & 10.6 & Sweeney \\
\hline $\begin{array}{l}\text { Bargaining with someone of the opposite gender is } \\
\text { more attractive for me }\end{array}$ & 0.769 & 2.31 & 1.287 & $\begin{array}{l}\text { and } \\
\text { Soutar }\end{array}$ \\
\hline $\begin{array}{l}\text { Bargaining with someone of the opposite gender is } \\
\text { easier for me }\end{array}$ & 0.849 & 2.38 & 1.310 & $(200 I)$ \\
\hline $\begin{array}{l}\text { Bargaining with someone of the opposite gender is } \\
\text { more beneficial for me }\end{array}$ & 0.695 & 2.25 & 1.195 & \\
\hline
\end{tabular}

The social value latent construct is explained by six attributes, where four yield the highest means: "Bargaining is a kind of culture" (3.07), "Bargaining on holidays is easier for me" (2.95), "I follow the recommendations of my peers to go with bargaining" (2.90) and "I bargain because this is what my friends also do" (2.85), suggesting that compliance and conformity with their peers is of utmost importance (Vigneron and Jonhson, 1999). Conversely, "Bargaining is a sort of entertainment" (2.70) and "Bargaining helps to express my self-identity" (2.08) are the least important factor. The consensus that shopping is an experience to that provides the opportunity to learn about the culture of the natives (Huang and Hsieh, 2011) and to be in conformity with peers is also evident in these results.

Gender differences as a latent construct are explained by attractiveness (2.31), easiness (2.38) or the benefits (2.25) of negotiating with the opposite gender. These results are in accordance with 
Table 3. Correlations matrix.

\begin{tabular}{lccccccc}
\hline & Return & $\begin{array}{c}\text { Previous } \\
\text { experience }\end{array}$ & $\begin{array}{c}\text { Transactional } \\
\text { value }\end{array}$ & $\begin{array}{c}\text { Emotional } \\
\text { value }\end{array}$ & $\begin{array}{c}\text { Social } \\
\text { value }\end{array}$ & $\begin{array}{c}\text { Gender } \\
\text { differences }\end{array}$ & Satisfaction \\
\hline Return & $\mathrm{I}$ & & & & & & \\
Previous experience & 0.34 & $\mathrm{I}$ & & & & & \\
Transactional value & 0.387 & 0.290 & $\mathrm{I}$ & & & & \\
Emotional value & 0.322 & 0.244 & 0.090 & $\mathrm{I}$ & & \\
Social value & 0.173 & 0.171 & 0.009 & 0.138 & 1 & & \\
Gender differences & 0.237 & 0.096 & 0.048 & 0.139 & 0.099 & 1 & \\
Satisfaction & 0.528 & 0.338 & 0.4643 & 0.371 & 0.156 & 0.193 & 1 \\
\hline
\end{tabular}

Amanatullah and Morris (2010) who suggest that negotiation strategies are more effective when the genders of the participants are different.

To test the hypothesis, the latent constructs derived were categorized in a three-point scale, to be regressed as explicative variables of the intention to return for bargaining purposes, that is also an ordinal variable. The option of a three-point scale arose on the low average means of the items and on the nodes of the variables considered. Given the ordinal nature of the responses, this problem lends itself to the use of an ordered probit model. This is a feasible model to use for latent, ordinal and dummy variables (Ben-Akiva et al., 1997). The cut-off of the model was set for the last category, which means very important. Stata 7 was used to estimate the model through a maximum likelihood function. The first step in the analysis was to examine the influence of the four values, satisfaction and previous bargain experiences over the respondents' return intentions for bargaining purposes.

Since the results show that different values influence return intentions (see Table 3 for the results of correlation analysis), the second step of the analysis included the estimation of an order probit regression and marginal effects in order to examine how transactional value, emotional, social values, gender differences, satisfaction and previous bargaining experiences influence return intentions for bargaining purposes. Table 4 summarizes the results of the econometric model estimated to measure the effects of these variables on the intention to return.

The log-likelihood value of the estimated order probit model is -705.96224 . The overall fit of the model is reasonably good, with a $\chi^{2}$ statistic value of 366.62 and a level of significance of 0.000 , due to the sample size. The model also presents a pseudo- $R^{2}=0.3059$. The good fits of the order probit model estimated allow us to compute the marginal effects. These represent the change in the probability of an observation being classified in each specific category of the dependent variable, according to the values of the predictors. The list of the independent variables, the respective coefficient, parameter significance and marginal effects are also presented in Table 4. The explanatory variables there test the six hypotheses outlined. Given the model specification, positive values for the parameters imply that the probability of returning to Sardinia for bargaining increases with increasing values in the respective variable. A negative value for the parameters implies a negative relationship.

With only two exceptions, we found a significant relationship with return intentions at $5 \%$ or even $1 \%$ significance level: Emotional value and gender differences show a mixed effect. The emotional value was not significant for those who value bargaining to return, and gender differences were not significant for those who value bargaining with the opposite gender as a determinant of 
Table 4. Estimation results for the Poisson regression model and marginal effects.

\begin{tabular}{|c|c|c|c|c|c|}
\hline & Coefficient & Standard error & $z$ & $p>z$ & $\Delta E(y / X)$ \\
\hline \multicolumn{6}{|l|}{ Transactional value } \\
\hline I & 0.643 & 0.119 & 5.40 & 0.000 & 0.176 \\
\hline 2 & 0.524 & 0.109 & 4.83 & 0.000 & 0.140 \\
\hline \multicolumn{6}{|l|}{ Emotional value } \\
\hline I & 0.492 & 0.113 & 4.36 & 0.000 & 0.138 \\
\hline 2 & 0.117 & 0.106 & 1.11 & 0.269 & 0.031 \\
\hline \multicolumn{6}{|l|}{ Social value } \\
\hline I & 0.240 & 0.108 & 2.22 & 0.026 & 0.064 \\
\hline 2 & 0.235 & 0.112 & 2.10 & 0.035 & 0.062 \\
\hline \multicolumn{6}{|l|}{ Gender differences } \\
\hline I & 0.498 & 0.109 & 4.59 & 0.000 & 0.137 \\
\hline 2 & 0.170 & 0.105 & 1.62 & 0.106 & 0.044 \\
\hline \multicolumn{6}{|l|}{ Satisfaction } \\
\hline I & 0.086 & 0.131 & 8.32 & 0.000 & 0.123 \\
\hline 2 & 0.449 & 0.104 & 4.33 & 0.000 & 0.336 \\
\hline Previous bargain experience & 0.279 & 0.074 & 3.76 & 0.000 & 0.07 \\
\hline
\end{tabular}

Table 5. Summary of results and hypothesis.

\begin{tabular}{lll}
\hline No. Hypothesis & Remarks \\
\hline I & $\begin{array}{l}\text { Transaction values positively influence return intentions with the purpose of bargaining } \\
2\end{array}$ & $\begin{array}{l}\text { Emotional values positively influence return intentions with the purpose of bargaining } \\
\text { Partially } \\
\text { supported }\end{array}$ \\
3 & $\begin{array}{l}\text { Social values positively influence return intentions with the purpose of bargaining } \\
\text { Gender differences in the bargaining game exchange positively influence return } \\
\text { intentions with the purpose of bargaining }\end{array}$ & $\begin{array}{l}\text { Supported } \\
\text { Supported }\end{array}$ \\
5 & $\begin{array}{c}\text { Satisfaction with the bargaining game exchange positively influences return intentions } \\
\text { with the purpose of bargaining }\end{array}$ & Supported \\
$6 \quad \begin{array}{c}\text { Previous bargain experiences positively influence return intentions with the purpose of } \\
\text { bargaining }\end{array}$ & Supported \\
\hline
\end{tabular}

return intentions (see Table 5 for the summary of results and the extent to which the hypotheses are supported).

As hypothesized, transactional value has a positive effect on expected return intentions for bargaining. This means that tourists with high concerns about economic issues and who are inherently rational tend to present a higher intention to revisit Sardinia to bargain. This confirms that Sardinia is a bargaining paradise for domestic tourists. This is an intuitive finding, as other researchers (e.g. Darke and Dahl, 2003) also prove that consumers involved in bargaining experiences have economic and rational concerns. This means that the low level of agreement with transactional value increases the likelihood of returning to bargain by 0.176 , whereas high levels of agreement with transactional values increases by the likelihood of returning to bargain by 0.140 . These results allow us to accept hypothesis 1 in accordance with Darke and Dahl's (2003) study. 
Transactional value plays a role in bargaining experience satisfaction that may enact the intention to repeat the experience.

Concerning hypothesis 2, the low emotional value most influences the likelihood to return (0.492), whereas the high level of emotional value does not moderate return intentions. Marginal effects reinforce this result, as a low level of agreement with emotional values increases return intentions to bargain by 0.138 . These results allow us to partially accept hypothesis 2 , reinforcing the fact that emotional values are critical in determine a good bargaining experience (Tsang et al., 2011). The difference in the coefficients may suggest that bargaining is more a form of innate than learned behaviour.

Hypothesis 3 proposes that return intentions to bargain are explained by tourists' social values. The results show that low social values are positive and have a statistically significant $(0.240)$ correlation with return intentions. Marginal effects show that low social value increases the propensity of return intentions to bargain by 0.064 , and high levels of social value increase the propensity of return intentions by 0.620 . This suggests that bargaining is a consensual social activity. Overall, hypothesis 3 is accepted.

Gender differences have captured the attention of several researchers. Amanatullah and Morris (2010) prove that negotiation with different genders leads to more effective negotiation. In the present case, hypothesis 4 establishes that gender differences influence return intentions to bargain. The results show mixed effects: Low gender differences are significant and positive (0.498). The marginal effect shows that this effect is 0.137 . High gender differences are non-significant $(0.170)$. This suggests that hypothesis 4 is partially accepted, and gender differences moderate satisfaction with the bargaining experience when buyers and sellers are of different genders.

Following the presupposition of Tsang et al. (2011), hypothesis 5 proposes that the more satisfied tourists are, the more likely they are to return to bargain. The results are significant: The tourists less satisfied with the bargaining experience intend to return to bargain, but at a slow pace (0.086), whereas the more satisfied tourists are more likely to return (0.449). Generally speaking, less satisfaction influences the intention to return to bargain by 0.123 , whereas among satisfied tourists, the likelihood to return increases (0.336). Hypothesis 5 is therefore accepted, suggesting that sellers may be educated to pamper tourists to the destination, promoting good interaction that may lead them to return.

Previous bargain experiences influence the intention to return to bargain (0.279), although marginal effects suggest that previous experience has a low marginal effect on the intention to return (0.07). As such, hypothesis 6 is accepted.

\section{Conclusion and implications}

Considered from the point of view of economics, the intention to engage in bargaining may result from the direct or indirect consequences of both the seller and the buyer expecting to benefit from a bilateral transaction experience. Such an economic experience thus forms part of the social culture of many communities around the globe. As the sellers' (supply) side could also potentially be central to from different research perspectives, this study has aimed to investigate tourists' bargaining motivation and its influence on their repeat visit intentions. According to the study findings, TU (e.g. value for money), emotions (e.g. feelings of happiness and self-confidence) and social values (e.g. the influence of others and other cultures) are more likely to influence tourists' bargain motivations and their repeat visit intentions. As such, the degree of economic benefit gained through bargaining, alongside the ability to express one's identity during a bargaining 
experience, are among the reasons which motivate tourists to engage in bargaining behaviour (e.g. Cheung et al., 2007; Kozak, 2015).

The study findings have theoretical implications from two perspectives, namely consumers' economic psychology and the economics of tourism. Firstly, the study contributes to the field of economic psychology, as the results provide empirical evidence that consumers seek utility, as well as emotional and social value, when involved in bargaining, and their (dis)satisfaction with their experiences are likely to influence future behavioural intentions. This finding corresponds with the results of previous bargaining studies in a tourism context (e.g. Kozak, 2015) and with the theory of reasoned action. Secondly, the study expands the literature on tourism economics by proposing that value for money becomes the prime expectation of utilitarian or rational tourist groups seeking product categories with higher quality at lower prices (e.g. Kozak, 2015; Tsang et al., 2011; Zeng et al., 2012; Zettelmeyer et al., 2006). This conclusion expresses the rational and economic nature of individuals' choices in tourism contexts (Morley, 1992) as in their daily economic lives. Above all, in essential shopping decisions undertaken in economic contexts, the negotiation process distracts consumers from considering other attributes (Gardner and Strang, 1984), and so rationalizes the purchase and emphasizes the utility of the perceived saving. Also, the greater likelihood of gaining value for money would be a utilitarian consequence of the negotiated price shifts (Kahneman and Tversky, 1982). The essence of rational behaviour is unlikely to be pronounced here, as there is evidence of gender differences, suggesting that rationality is not intrinsic to human nature and is likely to differ between males and females.

As for the list of benefits to consumers, in addition to enforcing self-confidence, gaining social interaction and value for money (e.g. Kozak, 2015; Tsang et al., 2011; Zeng et al., 2012), prior research indicates that the sense of such a victory over the seller leads to higher levels of post-purchase satisfaction (e.g. Allen et al., 1977). Furthermore, bargaining behaviour is considered to encompass the concept of social preferences and emotions (e.g. Civai et al., 2013). The intensity of bargaining in order to maintain psychological well-being has also been found to positively influence overall shopping satisfaction, intention/likelihood to return and recommendations (e.g. Tsang et al., 2011).

Taking this as a departure point, and turning back to the perspective of concrete implications, the study findings suggest various practical recommendations. Primarily, destination marketers should recognize the magnitude of consumers' attitudes towards bargaining behaviour when travelling and so should position their destinations to attract such traveller types. The findings suggest that destination marketers seeking to position themselves as a shopping destination could develop an online platform where tourists could share their shopping and bargaining experiences when visiting the destination, thus giving tips on how to bargain at the destination (Tsang et al., 2011). Secondly, to avoid risk perceptions, shops should invest in building consumer trust, delivering value and making customers feel that they are always winners in their business transactions. Finally, linked to relationship marketing, Price and Arnould (1999) suggest that commercial relationships that develop between service providers and customers are likely to be associated with overall customer satisfaction, service quality and positive word-of-mouth recommendations. Therefore, shopkeepers should create a kind of interactive atmosphere that creates room for those consumer groups who would like to socialize and relate more to the shopping experience. This experience may also directly or indirectly contribute to their well-being. This means that interaction between tourists and sellers offers a way of reviving the shopping experiences that malls, where interaction does not happen at all, have caused to diminish. As interaction is a game where the final result crosses the borders of economic theory, it is likely that this offers a way of reviving the shopping experiences and the shopping streets of destination tourists in a positive way. 


\section{Limitations and future research}

Although it makes significant theoretical and managerial contributions, the present study, like all studies, is not without limitations. The main limitation of the study lies in the fact that shopping is a cultural experience; it is therefore not possible to draw far-reaching conclusions proven from only one sample of domestic tourists. As such, the sample population is relatively homogeneous, limiting the possibility of demonstrating that socio-demographics influence bargaining experiences, as has previously been confirmed. Such a limitation also has its advantages, as the young population represent a generation for whom bargaining and interactions between consumers and sellers are less evident, because they are born into a generation where shopping malls remove the flexibility of those interactions that were previously considered traditional. A wider sample size would be required to compare the findings on the basis of cross-national differences. Furthermore, future research could investigate bargaining behaviour with respect to different types of products bought by consumers, their cultural backgrounds and contextual and situational factors (EugenioMartin and Campos-Soria, 2014; Tsang et al., 2011). As underscored by prior research on tourist behaviour (Jafari, 1987), there is a need to further investigate the extent to which tourists' bargaining behaviour as consumers at the destination can differ from their behaviour in their ordinary home environment. The number of people in the travel party or the preferences of family members could also be an additional factor in motivating people to bargain or to refrain from bargaining (Klawitter and Fletschner, 2011). Finally, depending on whether bargaining is or is not treated as the exclusive behaviour of tourists, future research could also compare people's attitudes towards bargaining in their daily life as consumers and as tourists on vacation.

\section{Declaration of conflicting interests}

The author(s) declared no potential conflicts of interest with respect to the research, authorship, and/or publication of this article.

\section{Funding}

The author(s) disclosed receipt of the following financial support for the research, authorship, and/or publication of this article: This research is granted by national funds by FCT - National Funding Agency for Science, Research and Technology under the project UID/ECO/04007/2013 CEFAGE.

\section{References}

Adams JS (1965) Inequity in social exchange. Advances in Experimental Social Psychology 2: 267-299.

Allen BH, Kahler RC, Tatham RL, et al. (1977) Bargaining process as a determinant of postpurchase satisfaction. Journal of Applied Research 62(4): 487-492.

Amanatullah ET and Morris MW (2010) Negotiating gender roles: gender differences in assertive negotiating are mediated by women's fear of backlash and attenuated when negotiating on behalf of others. Journal of Personality and Social Psychology 98(2): 256-267.

Arnold MJ and Reynolds KE (2003) Hedonic shopping motivations. Journal of Retailing 79: 77-95.

Bagozzi RP (1975) Marketing as exchange. Journal of Marketing 39: 32-39.

Bagozzi RP (1982) A field investigation of causal relations among cognitions, affect, intentions, and behavior. Journal of Marketing Research 19(4): 562-583.

Bearden WO and Etzel MJ (1982) Reference group influence on product and brand purchase decisions. Journal of Consumer Research 9(2): 183-194.

Bellenger D and Korgaonkar P (1980) Profiling the recreational shopper. Journal of Retail 56: 77-92.

Ben-Akiva M, McFadden M, Abe U, et al. (1997) Modeling methods for discrete choice analysis. Marketing Letters 8(3): 273-328. 
Bettman JR (1979) An Information Processing Theory of Consumer Choice. Reading: Addison Wesley.

Brucks M and Schurr PH (1990) The effects of bargainable attributes and attribute range knowledge on consumer choice processes. Journal of Consumer Research 16(4): 409-419.

Chang J, Yang B-T and Yu CG (2006) The moderating effect of salespersons' selling behaviour on shopping motivation and satisfaction: Taiwan tourists in China. Tourism Management 27(5): 934-942.

Charny D (1991) Published hypothetical bargains: the normative structure of contract interpretation. Michigan Law Review 89(7): 1815-1879.

Cheung MS, Anitsal MM and Anitsal I (2007) Revisiting word-of-mouth communications: a cross-national exploration. Journal of Marketing Theory and Practice 15(3): 235-249.

Civai C, Rumiati RI and Rustichini A (2013) More equal than others: equità norms as an integration of cognitive heuristics and contextual cues in bargaining games. Acta Psycologica 144: 12-18.

Cox AD, Cox D and Anderson RD (2005) Reassessing the pleasures of store shopping. Journal of Business Research 58(3): 250-259.

Dalrymple DJ, Cron WL and DeCarlo TE (2004) Sales Management. Hoboken: Wiley.

Darke PR and Dahl DW (2003) Fairness and discounts: the subjective value of a bargain. Journal of Consumer Psychology 13(3): 328-338.

Darke PR and Freedman JL (1995) Nonfinancial motives and bargain hunting. Journal of Applied Social Psychology 25: 1597-1610.

Draganska M, Klapper D and Villas-Boas SB (2010) A larger slice or a larger pie? An empirical investigation of bargaining power in the distribution channel. Marketing Science 29(1): 57-74.

Fischer S, Guth W and Pull K (2007) Is there as-if bargaining. The Journal of Socio-Economics 36: $546-560$.

Dillman D (1978) Mail and Telephone Surveys: The Total Design Method. Hoboken: John Wiley.

Eugenio-Martin JL and Campos-Soria JA (2014) Economic crisis and tourism expenditure cutback decision. Annals of Tourism Research 44: 53-73.

Falk P and Campbell C (eds) (1997) The Shopping Experience. London: Sage.

Fishbein M and Ajzen I (1975) Belief, attitude, intention and behavior: an introduction to theory and research. Reading: Addison-Wesley.

Gardner MP and Strang RA (1984) Consumer responses to promotions: some new perspectives. In: Kinnear TC (ed) Advances in Consumer Research. Vol. 11. Ann Arbor: Association for Consumer Research, pp. 420-425.

Grewal D, Monroe KB and Krishnan R (1998) The effects of price-comparison advertising on buyers' perceptions of acquisition value, transaction value, and behavioral intentions. Journal of Marketing 62(2): 46-59.

Holbrook MB, Chestnut RB, Oliva TA, et al. (1984) Play as a enjoyment of games. Journal of Consumer Research 11(2): 728-739.

Holbrook MB and Hirschman EC (1982) The experiential aspect of consumption: consumer fantasies, feelings, and fun. Journal of Consumer Research 9(2): 92-101.

Huang L and Hsieh YJ (2011) What drives consumer impulse buying? Evidence from a retail setting in Taiwan. Journal of International Management Studies 6(1): 151-158.

Hunt K (1993) CS/D and CB research suggestions and observations for the 1990s. Journal of Consumer Satisfaction, Dissatisfaction and Complaining Behavior 6: 40-42.

Jafari J (1987) Tourism models: the socio-cultural aspects. Tourism Management 82: 151-159.

Kahneman D and Tversky A (1982) The psychology of preferences. Scientific American 246: 161-173.

Kahneman D and Tversky A (1984) Choices, values, and frames. American Psychologist 39(4): 341-350.

Kahneman D, Knetsch JL and Thaler RH (1986) Fairness as a constraint on profit seeking: entitlements in the market. American Economic Review 76: 728-741.

Kennedy G (2008) Negotiation. Edinburgh: Edinburgh Business School, Heriot-Watt University.

Kim EY and Kim YK (2005) The effects of ethnicity and gender on teen's mall shopping motivations. International Textile \& Apparel Association 23(2): 65-77. 
Kim SS, Timothy DJ and Hwang J (2011) Understanding Japanese tourists' shopping preferences using the decision tree analysis method. Tourism Management 32(3): 544-554.

Klawitter M and Fletschner D (2011) Who is banked in low income families? The effect of gender and bargaining power. Social Science Research 40: 50-62.

Kozak M (2001) Repeaters' behavior at two distinct destinations. Annals of Tourism Research 28(3): $785-808$.

Kozak M (2015) Bargaining behaviour and the shopping experiences of British tourists on vacation. Journal of Travel \& Tourism Marketing 33(3): 313-325.

Law R and Au N (2000) Relationship modeling in tourism shopping: a decision rules induction approach. Tourism Management 21(3): 241-249.

Lehto XY, Cai LA, O'Leary JT, et al. (2004) Tourist shopping preferences and expenditure behaviours: the case of the Taiwanese outbound market. Journal of Vacation Marketing 10(4): 320-332.

Lichtenstein DR, Netemeyer RG and Burton S (1990) Distinguishing coupon proneness from value consciousness: an acquisition-transaction utility theory perspective. Journal of Marketing 54: 54-67.

Lo A and Qu H (2015) 'A theoretical model of the impact of a bundle of determinants on tourists' visiting and shopping intentions: a case of mainland Chinese tourists. Journal of Retailing and Consumer Services 22: 231-243.

McKercher B and Lui SL (2014) Becoming a tourist. International Journal of Tourism Research 16(4): 399-406.

Morley CL (1992) A microeconomic theory of international tourism demand. Annals of Tourism Research 19: 250-267.

Moschis GP (1976) Social comparison and informal group influence. Journal of Marketing Research 13(3): 237-244.

Murphy R, Ackermann K and Handgraaf M (2011) Measuring social value orientation. Judgment and Decision Making 6(8): 771-781.

Nash JF, Jr (1950) The bargaining problem. Econometrica 18: 155-162.

Park CW and Lessig VP (1977) Students and housewives: differences in susceptibility to reference group influences. Journal of Consumer Research 4(2): 102-110.

Pinar M, McCuddy K, Birkan I, et al. (2011) Gender diversity in the hospitality industry: an empirical study in Turkey. International Journal of Hospitality Management 30: 73-81.

Pizam A and Sussmann S (1995) Does nationality affect behavior?. Annals of Tourism Research 22(4): 901-917.

Price LL and Arnould EJ (1999) Commercial relationships: service provider-client relationships in context. Journal of Marketing 63: 38-56.

Proctor T (2000) Strategic marketing: an introduction. London: Routledge.

Schindler R (1989) The excitement of getting a bargain: some hypotheses concerning the origins and effects of smart-shopper feelings. Advances in Consumer Research 16: 447-453.

Schindler RM (1998) Consequences of perceiving oneself as responsible for obtaining a discount: evidence for smart-shopper feelings. Journal of Consumer Psychology 7: 371-392.

Sheth JN, Newman BI and Gross BL (1991) Why we buy what we buy: a theory of consumption values. Journal of Business Research 22(2): 159-170.

Souiden N (2002) Segmenting the Arab markets on the basis of marketing stimuli. International Marketing Review 19(6): 611-636.

Stigler GJ (1987) The Theory of Price. Chapters 15-16. New York: Macmillan.

Stone G (1954) City shoppers and urban identification: observations on the social psychology of city life. American Journal of Sociology 60: 36-45.

Sweeney J and Soutar GN (2001) Consumer perceived value: the development of a multiple item scale. Journal of Retailing 77(2): 203-220.

Tanguma J, Serviere L and Simpson C (2009) Shopping and bargaining in Mexico: the role of women. Journal of Applied Business and Economics 9(1): 34-40. 
Tauber E (1972) Why do people shop. Journal of Marketing 36: 46-59.

Thaler R (1985) Mental accounting and consumer choice. Marketing Science 4: 199-214.

Timothy D (2005) Shopping Tourism, Retailing and Leisure. Clevedon: Channel View.

Tsang N, Tsai H and Leung F (2011) A critical investigation of the bargaining behavior of tourists: the case of Hong Kong open-air markets. Journal of Travel \& Tourism Marketing 28(1): 27-47.

Turner LW and Reisinger Y (2001) Shopping satisfaction for domestic tourists. Journal of Retailing and Consumer Services 8(1): 15-27.

Varey RJ (2001) Marketing communication: an introduction to contemporary issues. Florence: Routledge.

Vigneron F and Johnson L (1999) A review and a conceptual framework of prestige-seeking consumer behavior. Academy of Marketing Science Review 9(1): 1-14.

Westbrook R and Black W (1985) A motivation-based shopper typology. Journal of Retail 61:78-103.

Wang D (2004) Hong Kongers' cross-border consumption and shopping in Shenzhen: patterns and motivations. Journal of Retailing and Consumer Services 11(3): 149-159.

Wong J and Law R (2003) Difference in shopping satisfaction levels: a study of tourists in Hong Kong. Tourism Management 24(4): 401-410.

Yuksel A (2007) Tourist shopping habitat: effects on emotions, shopping value and behaviours. Tourism Management 28(1): 58-69.

Yurtsever G, Azyurt B and Ben-Asher Z (2013) Gender differences in buyer-seller negotiations: emotion regulation strategies. Social Behavior and Personality 41(4): 569-576.

Zeng X, Dasgupta S and Weinberg CB (2012) How good are you at getting a lower price? A field study of the US automobile market. Journal of Consumer Policy 35: 255-274.

Zettelmeyer F, Morton FS and Silva-Risso J (2006) How the Internet lowers prices: evidence from matched survey and automobile transaction data. Journal of Marketing Research 43: 168-181. 